\title{
Rates of Nitrogen and Carbon Removal from Liquid Iron in Low Content Region under Reduced Pressures
}

\section{Kazuumi HARASHIMA, Shozo MIZOGUCHI, Michitaka MATSUO and Akihito KIYOSE1)}

Steelmaking Process, Process Technology Research Laboratories, Technical Development Bureau, Nippon Steel Corporation, Shintomi, Futtsu, Chiba-ken, 299-12 Japan. 1) Kimitsu R \& D Laboratory, Technical Development Bureau, Nippon Steel Corporation, Kimitsu, Kimitsu, Chiba-ken, 299-11 Japan.

(Received on June 12, 1991; accepted in final form on September 20,1991)

The kinetics of nitrogen and carbon removal from a liquid iron surface in low content regions by blowing Ar gas mixture under reduced pressures have been studied using the same vacuum induction furnace at $1600^{\circ} \mathrm{C}$, respectively. The results obtained are as follows:

(1) The nitrogen removal reaction is described as a second order reaction with respect to nitrogen content. The overall reaction rate constant, $k_{o v}^{N}$, decreases with the increase of total pressure, and oxygen and sulfur content.

Assuming that the nitrogen removal reaction progresses by a mixed control and that the chemical reaction for nitrogen gas formation is caused by adsorbed nitrogen atoms, the chemical reaction rate constant, $k_{r}^{\mathrm{N}}$, and the adsorption coefficient of oxygen, $\kappa_{0}$, and of sulfur, $\kappa_{S}$, are estimated as follows:

$$
\begin{gathered}
\mathrm{N}+\mathrm{N}=\mathrm{N}_{2}+\square \\
k_{r}^{\mathrm{N}}\left(=k_{[\mathrm{N}]} / f_{\mathrm{N}}^{2}\right) \mathrm{cm} / \mathrm{mass} \% / \mathrm{sec}=15 /\left(1+\kappa_{\mathrm{O}} \cdot a_{\mathrm{O}}+\kappa_{\mathrm{S}} \cdot a_{\mathrm{S}}\right)^{2}, \\
\kappa_{\mathrm{O}}=161, \quad \kappa_{\mathrm{S}}=63.4
\end{gathered}
$$

In the $\mathrm{Fe}-20$ mass $\% \mathrm{Cr}-0.2$ mass $\% \mathrm{C}-\mathrm{S}$ system also, the value of $k_{r}^{\mathrm{N}}$ can be expressed by the same equation. It is thus concluded that, macroscopically, the mechanism of nitrogen removal is the same irrespective of whether or not the melt contains chromium.

(2) In the carbon content range below $200 \mathrm{ppm}$, the overall carbon removal reaction rate constant, $k_{o v}^{C}$ exhibits a maximum value against oxygen content, and decreases with the increase of sulfur content.

Assuming that the chemical reaction for $\mathrm{CO}$ gas formation caused by the adsorbed carbon and the adsorbed oxygen atoms as a following equation, the dependence of the chemical reaction rate constant on oxygen and sulfur content is explained by the values of the adsorption coefficients $\kappa_{0}$ and $\kappa_{\mathrm{S}}$, respectively.

$$
\mathrm{C}+\mathrm{O}=\mathrm{CO}+\square
$$

The value of $\kappa_{0}$ is equal to about $100-300$ and that of $\kappa_{S}$ is equal to about $40-65$.

These values are in general accord with those determined from the nitrogen desorption reaction.

KEY WORDS: nitrogen removal; carbon removal; chemical reaction rate; adsorption coefficient; mixed control model; reduced pressure.

\section{Introduction}

To improve the quality of steel sheets, the carbon and nitrogen contents of the steel must be minimized. The ways to remove these impurities have been investigated vacuum degassing processes for secondary steel refining such as the RH and the DH processes.

Many fundamental studies have been reported about nitrogen removal ${ }^{1-6)}$ and carbon removal ${ }^{7,8)}$ from liquid iron under normal pressure, but only a few studies have been published on nitrogen removal ${ }^{9,10}$ and carbon removal $^{11)}$ under reduced pressure and in an ultra low-content region. Consequently, many aspects of the mechanisms of nitrogen and carbon removal reactions under these conditions remain unclear.

The present study measured the rates of nitrogen and carbon removal from the iron melt in low-nitrogen and low-carbon content regions under reduced pressures, using the same experimental apparatus. In the course of the study, the effects of oxygen and sulfur contents on the surface reaction rates were quantified, and the mechanisms of nitrogen and carbon removal reactions in low-content regions were examined.

\section{Experimental Procedure}

The experiments were carried out using a vacuum induction melting furnace $(3 \mathrm{kHz})$ containing $12 \mathrm{~kg}$ of 
iron melt in a magnesia crucible at $1600^{\circ} \mathrm{C}$ under reduced pressures. A schematic diagram of the experimental apparatus is shown in Fig. 1.

High purity electrolysis iron was used as raw material. The initial oxygen, sulfur, carbon and chromium content of the iron melt in each experiment was adjusted by adding iron oxide, sulfur, graphite and a metallic chromium, respectively. The initial nitrogen content was adjusted by controlling the nitrogen partial pressure, $P_{\mathrm{N}_{2}}$, at about $10 \mathrm{mmHg}$.

To investigate the effect of sulfur content on nitrogen removal, the initial carbon content was controlled at 0.2 mass $\%$ to keep the oxygen content low and constant.

During the nitrogen and carbon removal experiment, argon mixed gas was blown against the liquid iron surface through a lance with a nozzle diameter of $7.5 \mathrm{~mm}$ in order to minimize the influence of mass transfer in the gas diffusion boundary layer. The mixed gas blow rate and height were $20 \mathrm{~N} / / \mathrm{min}$ and $150 \mathrm{~mm}$, respectively. The total pressure, $P_{\text {total }}$, was controlled at $10 \pm 2 \mathrm{mmHg}$.

A gas mixture of Ar-5mass $\% \mathrm{~N}_{2}$ was used in the nitrogen removal experiments. Accordingly, the value of $P_{\mathrm{N}_{2}}$ was equal to $0.5 \pm 0.1 \mathrm{mmHg}$.

The other hand, $\mathrm{Ar}-20$ mass $\%\left(\mathrm{CO}-\mathrm{CO}_{2}\right)$ gas mixture was blown in the carbon removal experiment. The value of $\mathrm{CO} / \mathrm{CO}_{2}$ mass ratio was $0.5-1.9$. The purity of each gases used was above than 99.99 mass $\%$.

For comparison with the results of the gas blowing experiment, some removal experiments were carried out under high vacuum pressure $\left(2 \times 10^{-3} \mathrm{mmHg}\right)$ without

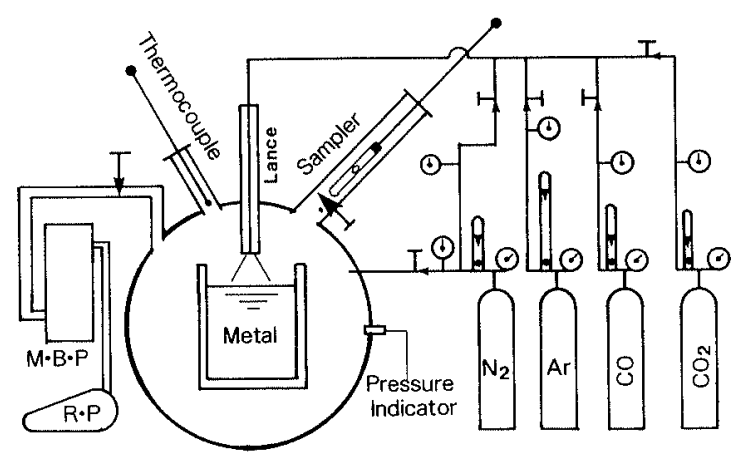

Fig. 1. Schematic diagram of experimental apparatus.

Table 1. Experimental conditions.

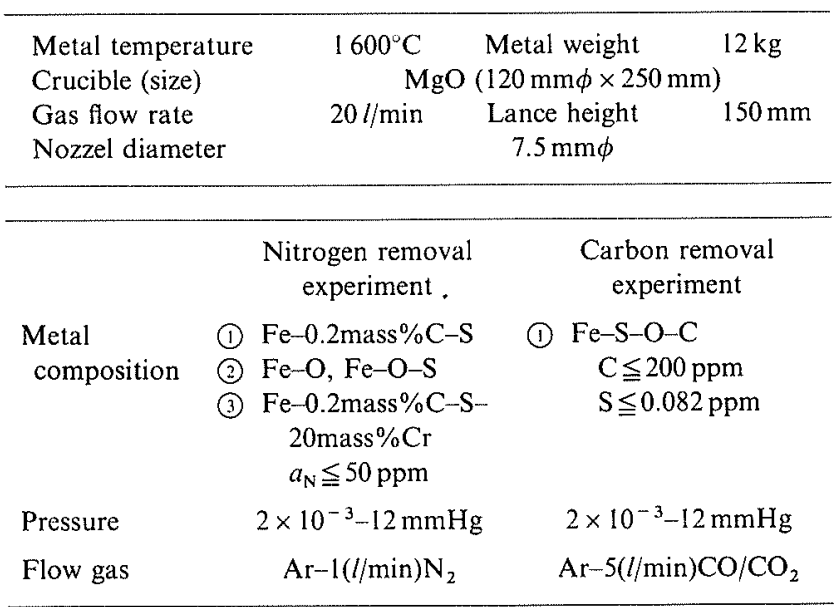

gas blowing.

The experimental conditions are listed in Table $\mathbf{1 .}$

Metal samples were taken with a quartz tube, and nitrogen and carbon content in the samples was analyzed by the thermoconductometric method after melting in a current of inert gas, and by the infrared absorptiometric method after combustion in the current of oxygen (high sensitivity type).

\section{Experimental Results}

Under the experimental conditions used, no gas evolution was observed in the liquid iron. The nitrogen and carbon removal reaction sites could thus be surmised to be the gas/metal interface.

\subsection{Nitrogen Removal Rate}

The nitrogen removal rate from liquid iron can be approximated by a second-order reaction with respect to nitrogen content as Eq. (1) irrespective of the type of liquid iron.

$$
-\frac{d[\mathrm{~N}]}{d t}=\left(\frac{A}{V}\right) \cdot k_{o v}^{\mathrm{N}} \cdot\left([\mathrm{N}]_{t}^{2}-[\mathrm{N}]_{e}^{2}\right)
$$

where $A:$ gas-liquid iron contact area $\left(\mathrm{cm}^{2}\right)$

$$
V \text { : volume of liquid iron }\left(\mathrm{cm}^{3}\right)
$$

$[\mathrm{N}]_{t}$ : nitrogen content in liquid iron at time $t$ (mass \%)

$[\mathrm{N}]_{e}$ : equilibrium nitrogen content in liquid iron with nitrogen partial pressure (mass \%)

$k_{o v}^{\mathrm{N}}$ : overall reaction rate constant for nitrogen removal $(\mathrm{cm} / \mathrm{mass} \% / \mathrm{sec})$

$t$ : time (sec).

Figure 2 shows the influence of total pressure, $P_{\text {total }}$, on the overall reaction rate constant, $k_{o v}^{\mathrm{N}}$, in 0.2 mass $\%[C]$ iron melt by the gas blowing. Even with a

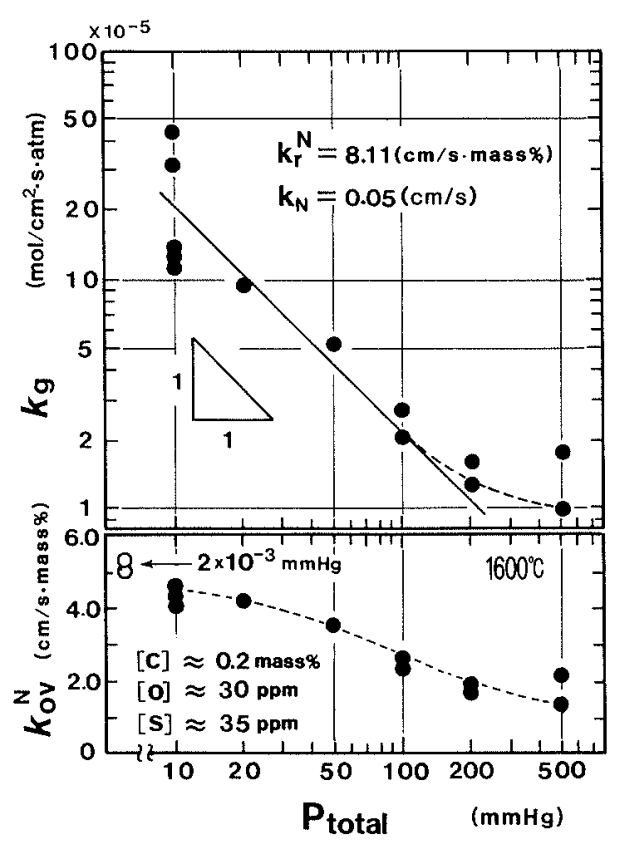

Fig. 2. Influence of total pressure on overall reaction rate constant, $k_{o w}^{\mathrm{N}}$, of nitrogen removal and on mass transfer coefficient, $k_{g}$, of $\mathrm{N}_{2}$ in gas diffusion boundary layer. 


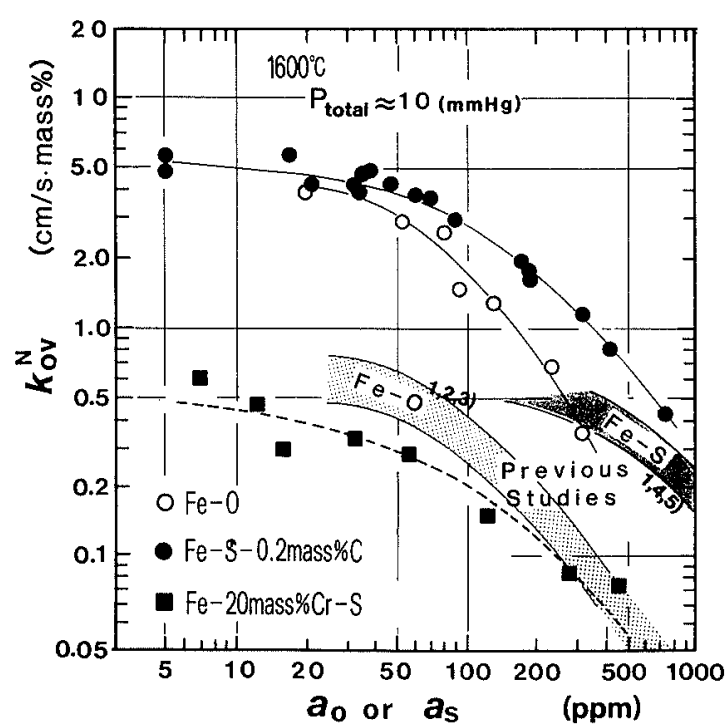

Fig. 3. Influence of oxygen activity, $a_{0}$, and sulfur activity, $a_{\mathrm{s}}$, on overall reaction rate constant of nitrogen removal, $k_{o v}^{\mathrm{N}}$

gas blowing rate of $20(\mathrm{~N} l / \mathrm{min})$, the value of $k_{o v}^{\mathrm{N}}$ decreases with the increase of $P_{\text {total }}$. This fact suggests that the value of resistance in the gas diffusion boundary layer including "the detachment reaction from the surface resistance of adsorbed nitrogen molecule at the metal surface"1,12) is too large to be ignored at the pressure of $500 \mathrm{mmHg}$. For comparison, the value of $k_{o v}^{\mathrm{N}}$ measured under a high vacuum pressure without gas blowing is shown by open circles in Fig. 2. This value is slightly greater than that measured under the pressure of $10 \mathrm{mmHg}$ with gas blowing.

Figure 3 shows the influence of activities of oxygen, $a_{\mathrm{O}}$, and of sulfur, $a_{\mathrm{S}}$, on $k_{o v}^{\mathrm{N}}$ observed under the pressure of $10 \mathrm{mmHg}$ with gas blowing. The value of $k_{o v}^{\mathrm{N}}$ strongly depends on the value of $a_{\mathrm{O}}$ or $a_{\mathrm{S}}$ and decreases with the increase of $a_{\mathrm{O}}$ or $a_{\mathrm{S}}$, respectively.

The degree of harmful influence of oxygen on the nitrogen removal rate is greater than that of sulfur, but the activities of both were calculated using the values of activity coefficient of each element based on thermochemical data. ${ }^{13)}$

The values of $k_{o v}^{\mathrm{N}}$ at low-oxygen and low-sulfur activity region observed in the present work are greater than those in previous studies. ${ }^{1-6,9)}$

The relation between $k_{o v}^{\mathrm{N}}$ of $\mathrm{Fe}-20 \mathrm{mass} \% \mathrm{Cr}-0.2$ mass $\% \mathrm{C}-\mathrm{S}$ system and $a_{\mathrm{S}}$ is shown in Fig. 3 as solid squares. The value of $k_{o v}^{\mathbf{N}}$ also decreases with the increase of $a_{\mathrm{S}}$, and the actual value of $k_{o v}^{\mathrm{N}}$ is about 0.1 times smaller than the value of $k_{o v}^{\mathrm{N}}$ obtained no chromium containing system. However, the degree of harmful influence of the sulfur on $k_{o v}^{\mathrm{N}}$ is very similar to that observed in the $\mathrm{Fe}-0.2 \mathrm{mass} \% \mathrm{C}-\mathrm{S}$ system.

\subsection{Carbon Removal Rate}

Figure 4 shows typical changes in the carbon and oxygen content of the ultra low sulfur iron melt during $\mathrm{Ar}-\mathrm{CO}-\mathrm{CO}_{2}$ gas blowing. The carbon removal reaction behavior was divided into three regions.

(1) In the range of carbon content higher than about

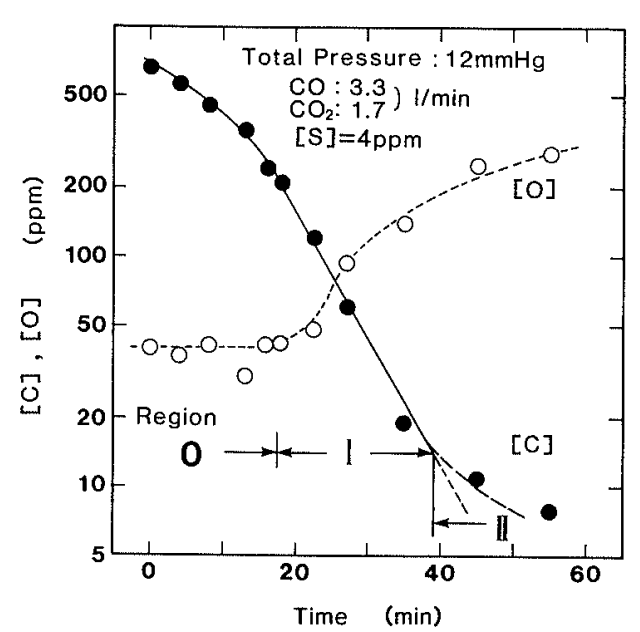

Fig. 4. Changes in carbon and oxygen content in iron melt during $\mathrm{Ar}-\mathrm{CO}-\mathrm{CO}_{2}$ blowing.

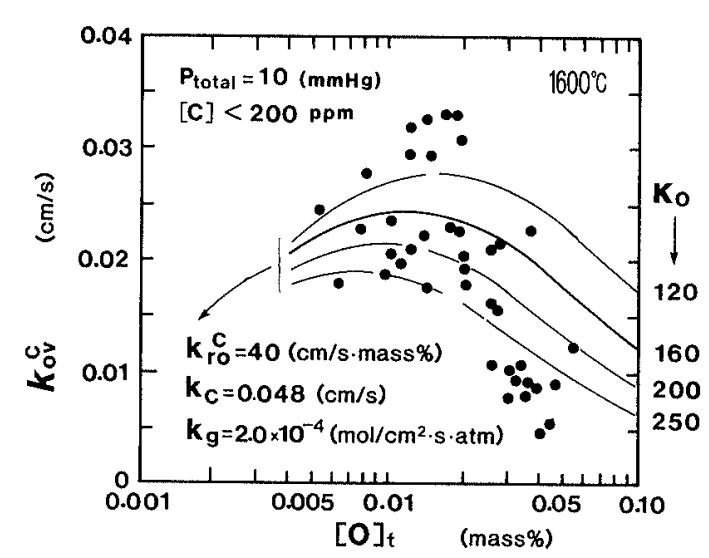

Fig. 5. Influence of oxygen content on $k_{o v}^{\mathrm{c}}$ at various times during $\mathrm{Ar}-\mathrm{CO}-\mathrm{CO}_{2}$ blowing.

$200 \mathrm{ppm}$, the rate of carbon removal was described as zeroth order reaction with respect to carbon content, and oxygen content remained constant at about $40 \mathrm{ppm}$, "Region-0".

(2) In the range of carbon content between about 10 and $200 \mathrm{ppm}$, the rate can be apparently approximated by a first-order reaction with respect to carbon content, and oxygen content was increased, "Region-I".

(3) With carbon content less than about $10 \mathrm{ppm}$, the rate is less than that in "Region-I", and the oxygen content is more than 150 ppm, "Region-II".

The carbon removal behavior in "Region-0". was previously explained, ${ }^{14)}$ so the details are abbreviated in this paper.

Kishimoto et al. ${ }^{11)}$ reported that the overall reaction rate constant for carbon removal, $k_{o v}^{\mathrm{c}}$, decreased with the decrease of carbon content at less than 0.005 mass $\%$.

Figure 5 shows the effect of oxygen conent on the value of $k_{o v}^{\mathrm{C}}$, observed in melts with sulfur content of less than $5 \mathrm{ppm}$ in Regions-I and -II. The value of $k_{o v}^{\mathrm{C}}$ was calculated by Eq. (2) from the carbon content between the analysis points.

$$
-\frac{d[\mathrm{C}]}{d t}=\left(\frac{A}{V}\right) \cdot k_{o v}^{\mathrm{C}} \cdot\left([\mathrm{C}]_{t}-[\mathrm{C}]_{e}\right)
$$

where, $[\mathrm{C}]_{t}$ : carbon content in liquid iron at time $t$ 


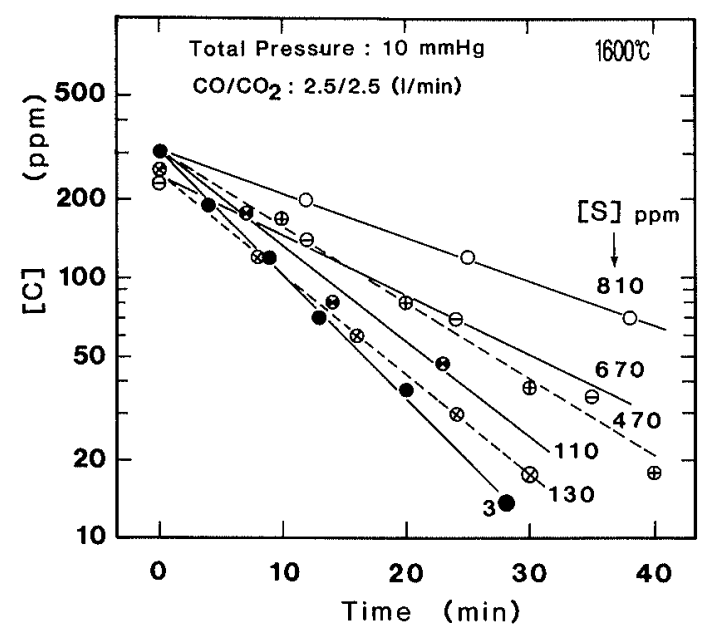

Fig. 6. Influence of sulfur content on change in carbon content in Region-I.

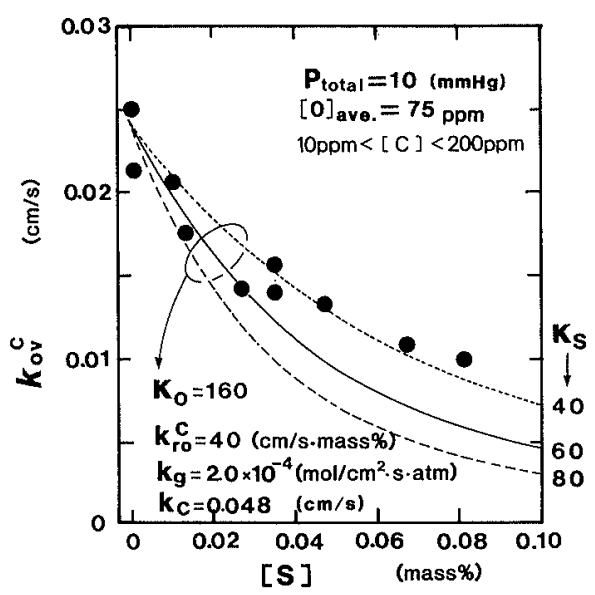

Fig. 7. Influence of sulfur content on $k_{\mathrm{ov}}^{\mathrm{c}}$.

$$
\text { (mass \%) }
$$

$[\mathrm{C}]_{e}$ : equilibrium carbon content in liquid iron with $\mathrm{CO}$ partial pressure and oxygen content in liquid iron (mass $\%$ )

$k_{o v}^{\mathrm{C}}$ : overall reaction rate constant for carbon removal $(\mathrm{cm} / \mathrm{sec})$.

The value of $k_{o v}^{\mathrm{c}}$ becomes maximum when oxygen content is 0.01 to 0.02 mass $\%$ and decreases with further increase in oxygen content. Thus, progress of the carbon removal reaction from the surface of liquid iron in the low carbon content region is apparently retarded by the increase in oxygen content.

Figure 6 shows the changes in carbon content of liquid iron containing various sulfur during $\mathrm{Ar}-\mathrm{CO}-\mathrm{CO}_{2}$ gas blowing under the pressure of $10 \mathrm{mmHg}$. The type of carbon removal behavior in this carbon content region corresponds to that in Region-I, and the value of minimum carbon content is not reached within $10 \mathrm{ppm}$. Namely, in this region, the rate of reaction is described as a first order reaction with respect to carbon content.

Figure 7 shows the influence of sulfur content on the average overall relation rate constant for the carbon removal, $k_{o v}^{\mathrm{C}}$, this is determined from the slope of the straight line in Fig. 6. The value of $k_{o v}^{\mathrm{C}}$ decreases with the increase of sulfur content. In this case, the oxygen

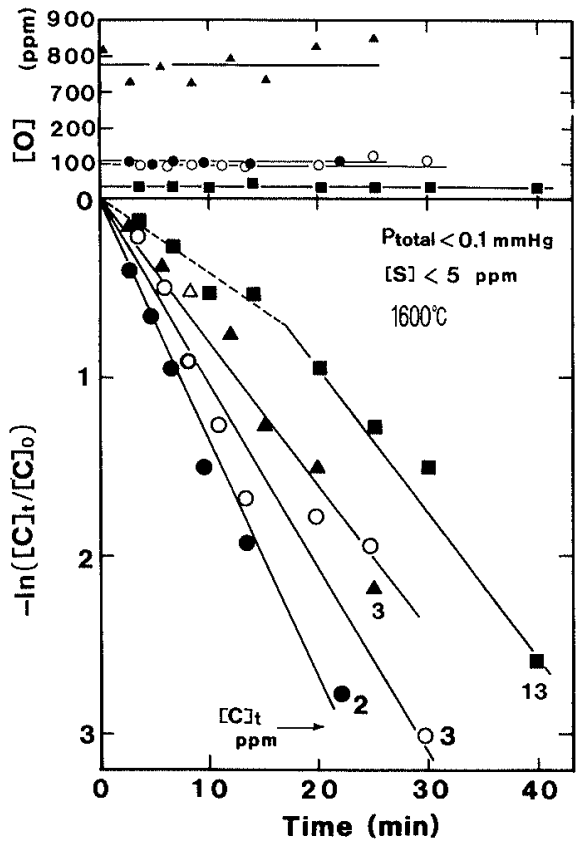

Fig. 8. Change of oxygen content and $-\ln \left([\mathrm{C}]_{t} /[\mathrm{C}]_{o}\right)$ under high vacuum pressure.

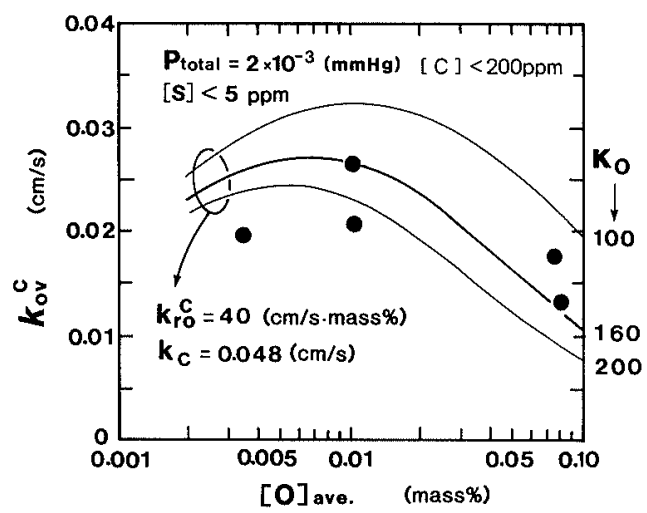

Fig. 9. Influence of average oxygen content on $k_{\mathrm{ov}}^{\mathrm{c}}$ under high vacuum pressure.

content increased from 50 to $150 \mathrm{ppm}$.

With $\mathrm{Ar}-\mathrm{CO}-\mathrm{CO}_{2}$ gas blowing, oxygen content in Regions-I and -II increased. In order to prevent this increase, it was decided to perform a carbon removal experiment under a high vacuum pressure $\left(2 \times 10^{-3}\right.$ $\mathrm{mmHg}$ ) without $\mathrm{Ar}-\mathrm{CO}-\mathrm{CO}_{2}$ gas blowing, and thereby to confirm the effect of oxygen content on the carbon removal reaction.

Figure 8 shows the change of $-\ln \left([\mathrm{C}]_{t} /[\mathrm{C}]_{o}\right)$ and $[\mathrm{O}]$ in that experiment. The changes of $-\ln \left([\mathrm{C}]_{t} /[\mathrm{C}]_{0}\right)$ are in close agreement with the straight line against the time down to extremely low carbon content of 2 ppm. In this experiment, oxygen content was remained almost constant during the entire period of carbon removal.

The relation between $k_{o v}^{\mathrm{C}}$ as determined from the slopes of the straight lines in Fig. 8 and average oxygen content is shown in Fig. 9. Influence of oxygen content on $k_{o v}^{\mathrm{C}}$ is similar to that in the case of $\mathrm{Ar}-\mathrm{CO}-\mathrm{CO}_{2}$ blowing, so, the value of $k_{o v}^{\mathrm{C}}$ becomes maximum relative to oxygen content. 


\section{Discussion}

In investigating the rate of gas/metal reaction between a liquid iron and a gas in the region where the element of interest is low in content, it is very important to estimate:

1) the value of mass transfer coefficient in the gas diffusion boundary layer, $k_{g}$,

2) the value of mass transfer coefficient in the metal diffusion boundary layer, $k_{X}$, and

3) the value of the chemical reaction rate constant at the interface of the gas/metal, $k_{r}$.

Particularly when the content of the element to be removed is low, estimation of the chemical reaction rate constant is important to decide the rate controlling step of the reaction.

Assuming that the respective reaction proceeds as controlled by the mass transfer in the metal and gas phases and the chemical reaction at the gas/metal interface, the value of $k_{o v}^{\mathrm{N}}$ and $k_{o v}^{\mathrm{C}}$ is generally expressed by the following equations.

๑ Nitrogen Removal (2nd order rate) ${ }^{9)}$

The nitrogen removal rates of three steps are expressed as follows:

o metal phase mass transfer

$$
-n_{M}\left(\equiv \frac{d \mathrm{~N}_{\mathrm{N}}}{d t}\right)=A \cdot k_{\mathrm{N}} \cdot\left([\mathrm{N}]_{b}-[\mathrm{N}]_{i}\right) \quad(\mathrm{mol} / \mathrm{sec})
$$

o chemical reaction rate at the interface

$$
-n_{r}\left(\equiv \frac{d \mathrm{~N}_{\mathrm{N}}}{d t}\right)=A \cdot k_{[\mathrm{N}]} \cdot\left([\mathrm{N}]_{i}^{2}-[\mathrm{N}]_{l}^{2}\right) \quad(\mathrm{mol} / \mathrm{sec})
$$

o gas phase mass transfer

$$
-n_{g}\left(\equiv \frac{d \mathrm{~N}_{\mathrm{N}_{2}}}{d t}\right)=A \cdot k_{g} \cdot\left(P_{\mathrm{N}_{2}}^{i}-P_{\mathrm{N}_{2}}^{b}\right) \quad(\mathrm{mol} / \mathrm{sec})
$$

- material balance equation

$$
2 n_{g}=n_{r}=n_{M}
$$

Considering the equilibrium nitrogen content in metal with the nitrogen partial pressure in gas phase, the value of $k_{o v}^{\mathrm{N}}$ is expressed by Eq. (7).

$$
\begin{aligned}
& k_{o v}^{\mathrm{N}}=k_{\mathrm{N}} \cdot\left(\frac{2[\mathrm{~N}]+\phi-\sqrt{\phi^{2}+4[\mathrm{~N}] \cdot \phi+4[\mathrm{~N}]_{e}^{2}}}{2\left([\mathrm{~N}]^{2}-[\mathrm{N}]_{e}^{2}\right)}\right) \\
&\left(\mathrm{cm}^{4} / \mathrm{mol} / \mathrm{sec}\right) \ldots \ldots \ldots \\
& \phi=k_{\mathrm{N}} \cdot\left(\frac{K_{\mathrm{N}_{2}}^{2}}{2 k g}+\frac{1}{k_{[\mathrm{N}]}}\right)=\frac{([\mathrm{N}] \cdot \lambda-1)^{2}-\lambda^{2} \cdot[\mathrm{N}]_{e}^{2}}{\lambda} \\
& \lambda=\frac{k_{o v}^{\mathrm{N}}}{k_{\mathrm{N}}} \ldots \ldots \ldots \ldots \ldots \ldots \ldots \ldots \ldots \ldots \ldots \ldots \ldots \ldots \ldots \ldots \ldots
\end{aligned}
$$

where, $k_{\mathrm{N}}$ : mass transfer coefficient of nitrogen atom $(\mathrm{cm} / \mathrm{sec})$

$k_{\text {[N] }}$ : apparent chemical reaction rate constant $\left(\mathrm{cm}^{4} / \mathrm{mol} / \mathrm{sec}\right)$

$k_{q}$ : mass transfer coefficient of nitrogen molecule $\left(\mathrm{mol} / \mathrm{cm}^{2} / \mathrm{sec} / \mathrm{atm}\right)$

$K_{\mathrm{N}_{2}}$ : equilibrium constant for $2[\mathrm{~N}]=\mathrm{N}_{2}(\mathrm{~g})(\mathrm{mol} /$

$$
\mathrm{cm}^{3} / \mathrm{atm}^{1 / 2} \text { ) }
$$

$[\mathrm{N}]_{b}$ : nitrogen content in metal bulk $\left(\mathrm{mol} / \mathrm{cm}^{3}\right)$

$[\mathrm{N}]_{i}$ : nitrogen content in metal at the interface $\left(\mathrm{mol} / \mathrm{cm}^{3}\right)$

$[\mathrm{N}]_{l}$ : equilibrium nitrogen content in metal with the nitrogen partial pressure at the interface $\left(\mathrm{mol} / \mathrm{cm}^{3}\right)$

$[\mathrm{N}]_{e}$ : equilibrium nitrogen content in metal with the nitrogen partial pressure of gas bulk $\left(\mathrm{mol} / \mathrm{cm}^{3}\right)$

$P_{\mathrm{N}_{2}}^{b}$ : nitrogen partial pressure of gas bulk (atm)

$P_{\mathrm{N}_{2}}^{i}$ : nitrogen partial pressure at the interface (atm).

( ) Carbon Removal (1st order rate) ${ }^{8)}$

The carbon removal rates of three steps are expressed as follows:

o metal phase mass transfer

$-n_{M}\left(\equiv \frac{d \mathrm{~N}_{\mathrm{C}}}{d t}\right)=A \cdot k_{\mathrm{C}} \cdot\left([\mathrm{C}]_{b}-[\mathrm{C}]_{i}\right) \quad(\mathrm{mol} / \mathrm{sec})$

o chemical reaction rate at the interface

$-n_{r}\left(\equiv \frac{d \mathrm{~N}_{\mathrm{C}}}{d t}\right)=A \cdot k_{r} \cdot\left([\mathrm{C}]_{i} \cdot[\mathrm{O}]_{i}-\frac{P_{\mathrm{CO}}^{i}}{K_{\mathrm{CO}}}\right) \quad(\mathrm{mol} / \mathrm{sec})$

$\therefore$ gas phase mass transfer

$$
-n_{g}\left(\equiv \frac{d \mathrm{~N}_{\mathrm{C}}}{d t}\right)=A \cdot k_{g} \cdot\left(P_{\mathrm{CO}}^{i}-P_{\mathrm{CO}}^{b}\right) \quad(\mathrm{mol} / \mathrm{sec})
$$

o material balance equation

$$
n_{g}=n_{r}=n_{M}
$$

Considering that the mass transfer rate of oxygen atom is much greater than that of carbon atom, the value of $k_{o v}^{\mathrm{N}}$ is expressed by Eq. (14).

$$
\begin{gathered}
k_{o v}^{\mathrm{C}}=\frac{\left(k_{g r} \cdot[\mathrm{O}]\right) \cdot k_{\mathrm{C}}}{\left(k_{g r} \cdot[\mathrm{O}]+k_{\mathrm{C}}\right)} \\
k_{g r}=\frac{\left(K_{\mathrm{CO}} \cdot k_{g}\right) \cdot k_{\mathrm{r}}^{\mathrm{C}}}{\left(K_{\mathrm{CO}} \cdot k_{g}\right)+k_{r}^{\mathrm{C}}}
\end{gathered}
$$

where, $k_{\mathrm{C}}$ : mass transfer coefficient of carbon atom $(\mathrm{cm} / \mathrm{sec})$

$k_{r}^{\mathrm{c}}$ : chemical reaction rate constant for carbon removal $\left(\mathrm{cm}^{4} / \mathrm{mol} / \mathrm{sec}\right)$

$K_{\mathrm{CO}}$ : equilibrium constant for $[\mathrm{C}]+[\mathrm{O}]=\mathrm{CO}(\mathrm{g})$ $\left(\mathrm{mol}^{2} / \mathrm{cm}^{6} / \mathrm{atm}\right)$

$k_{g}$ : mass transfer coefficient of $\mathrm{CO}$ molecule $\left(\mathrm{mol} / \mathrm{cm}^{2} / \mathrm{sec} / \mathrm{atm}\right)$

[O]: oxygen content $\left(\mathrm{mol} / \mathrm{cm}^{3}\right)$

$[\mathrm{C}]_{b}$ : carbon content in metal bulk $\left(\mathrm{mol} / \mathrm{cm}^{3}\right)$

$[\mathrm{C}]_{i}$ : carbon content in metal at the interface $\left(\mathrm{mol} / \mathrm{cm}^{3}\right)$

$[\mathrm{C}]_{e}$ : equilibrium carbon content in metal with the value of $P_{\mathrm{Co}}$ at the gas bulk and oxygen content $\left(\mathrm{mol} / \mathrm{cm}^{3}\right)$

$P_{\mathrm{CO}}^{b}$ : partial pressure of carbon monoxide in gas bulk (atm)

$P_{\mathrm{CO}}^{i}$ : partial pressure of carbon monoxide at the interface (atm). 


\subsection{Estimation of the Mass Transfer Coefficient of the Gas Diffusion Boundary Layer under Reduced Pres- sures in Gas Blowing}

Choh et al. ${ }^{9)}$ conducted experiments using a furnace of practically the same type and size as that used in the present experimental work, and reported $0.050-0.068 \mathrm{~cm} /$ $\mathrm{sec}$ as the value of the mass transfer coefficient of nitrogen atom, $k_{\mathrm{N}}$. Hence, the value of $k_{\mathrm{N}}$ is adopted as $0.050 \mathrm{~cm} / \mathrm{sec}$ and is also used to determine the mass transfer coefficient of nitrogen molecules.

Under high vacuum pressure, the mean free path of the nitrogen molecule is considered sufficiently larger than the length from liquid iron surface to the top of the crucible. So, assuming that the rate determining step of the nitrogen removal reaction under the condition of $2 \times 10^{-3} \mathrm{mmHg}$ is mixed control of the mass transfer of nitrogen atom and chemical reaction at the gas/metal interface described by Eq. (17), the average value of $k_{r} \fallingdotseq k_{[\mathrm{N}]}$ plotted in Fig. 2 as open circles can be decided as $8.1(\mathrm{~cm} / \mathrm{sec} / \mathrm{mass} \%)=1620\left(\mathrm{~cm}^{4} / \mathrm{sec} / \mathrm{mol}\right)$. The value of $k_{[\mathrm{N}]}$ was calculated by using the value of $[\mathrm{N}]=0.0020$ mass $\%=1.0 \times 10^{-5} \mathrm{~mol} / \mathrm{cm}^{3}$. The unit was unified in the calculation to decide the value of $k_{[\mathrm{N}]}$. Substituting those values into Eqs. (7)-(9), the values of $k_{g}$ under each pressure can be calculated. Figure 2 shows the relation between $k_{g}$ and $P_{\text {total }}$. The value of $k_{g}$ is inversely proportional to $P_{\text {total }}$. Generally, the value of $k_{g}$ is expressed as

$$
k_{g}=D_{\mathrm{Ar}-\mathrm{N}_{2}} / \delta, \quad D_{\mathrm{Ar}-\mathrm{N}_{2}} \propto 1 / P_{\text {total }}^{15)}
$$

where, $D_{\mathrm{Ar}-\mathrm{N}_{2}}$ : diffusivity of nitrogen molecule in Ar.

As the value of gas blowing rate is constant, it is considered that the thickness of gas diffusion boundary layer, $\delta$, is maintained as a constant value. ${ }^{15)}$ Accordingly, the dependence of the value of $k_{g}$ on $P_{\text {total }}$ is a reasonable result. So, in the condition of a $20(\mathrm{~N} l / \mathrm{min})$ gas blowing rate under $10 \mathrm{mmHg}$ pressure, the value of $k_{g}$ is equal to $2.0 \times 10^{-4}\left(\mathrm{~mol} / \mathrm{cm}^{2} / \mathrm{sec} / \mathrm{atm}\right)$.

It should be noted that even when the gas is blown at the rate of $20 \mathrm{~N} l / \mathrm{min}$, the gas phase presents resistance equivalent to about $1 \times 10^{-5}\left(\mathrm{~mol} / \mathrm{cm}^{2} / \mathrm{sec} / \mathrm{atm}\right)$ under the vicinity of normal pressure.

\subsection{Influencè of Oxygen and Sulfur Content on Chemical Reaction Rate}

Assuming that the chemical reaction of nitrogen desorption and of $\mathrm{CO}$ gas formation at the liquid iron surface are described by Eqs. (17) ${ }^{1)}$ and (19), and that the value of $\left(1+\kappa_{\mathrm{S}} \cdot a_{\mathrm{S}}+\kappa_{\mathrm{O}} \cdot a_{\mathrm{O}}\right)$ is so much greater than the value of $\left(\kappa_{\mathrm{C}} \cdot a_{\mathrm{C}}+\kappa_{\mathrm{N}} \cdot a_{\mathrm{N}}\right)$, the chemical reaction rate constants are expressed by Eqs. $(18)^{1)}$ and (20), respectively.

$$
\begin{gathered}
\mathrm{N}+\mathrm{N}=\mathrm{N}_{2}+\square \\
k_{r}^{\mathrm{N}}=\frac{k_{[\mathrm{N}]}}{f_{\mathrm{N}}^{2}}=\frac{k_{r o}^{\mathrm{N}}}{\left(1+\kappa_{\mathrm{S}} \cdot a_{\mathrm{S}}+\kappa_{\mathrm{O}} \cdot a_{\mathrm{O}}\right)^{2}} \\
\mathrm{C}+\mathrm{O}=\mathrm{CO}+\square \\
k_{r}^{\mathrm{C}}=\frac{k_{r o}^{\mathrm{C}}}{\left(1+\kappa_{\mathrm{S}} \cdot a_{\mathrm{S}}+\kappa_{\mathrm{O}} \cdot a_{\mathrm{O}}\right)^{2}}
\end{gathered}
$$

where,

$$
\begin{aligned}
\square & : \text { adsorption site } \\
k_{r o}^{\mathrm{N}}: & \begin{array}{l}
\text { chemical reaction rate constant for ni- } \\
\text { trogen removal from pure liquid iron }
\end{array} \\
k_{r o}^{\mathrm{C}}: & \begin{array}{l}
\text { chemical reaction rate constant for carbon } \\
\text { removal from pure liquid iron }
\end{array} \\
\kappa_{X}: & \text { adsorption coefficient of element } X \text { in } \\
& \text { liquid iron } \\
a_{X}: & \text { activity of } X \text { element in liquid iron. }
\end{aligned}
$$

The chemical reaction rate constant $k_{r}^{\mathrm{N}}$ is first discussed. Substituting the following values into Eqs. (7)-(9), the value of the apparent chemical reaction rate constant, $k_{[\mathrm{N}]}$, can be calculated from the value of $k_{o v}^{\mathrm{N}}$ at the pressure of $10 \mathrm{mmHg}$.

$k_{g}=2 \times 10^{-4}\left(\mathrm{~mol} / \mathrm{cm}^{2} / \mathrm{sec} / \mathrm{atm}\right), \quad k_{\mathrm{N}}=0.050(\mathrm{~cm} / \mathrm{sec})$

Accordingly, the value of $k_{r}^{\mathrm{N}}$ can be determined by Eq. (18) from the activity coefficient, $f_{\mathrm{N}} \cdot{ }^{13)}$

When the method of least squares is applied to the data of the $\mathrm{Fe}-\mathrm{O}$ and $\mathrm{Fe}-\mathrm{S}-0.2 \mathrm{mass} \% \mathrm{C}$ system according to Eq. (21), the values of $\kappa_{\mathrm{O}}, \kappa_{\mathrm{S}}$ and $k_{r o}^{\mathrm{N}}$ can be determined.

$$
\frac{1}{\sqrt{k_{r}^{\mathrm{N}}}}=\frac{\left(1+\kappa_{\mathrm{O}} \cdot a_{\mathrm{O}}+\kappa_{\mathrm{S}} \cdot a_{\mathrm{S}}\right)}{\sqrt{k_{r o}^{\mathrm{N}}}}
$$

The respective values of $\kappa_{\mathrm{O}}$ and of $\kappa_{\mathrm{S}}$ were:

$$
\kappa_{\mathrm{O}}=161, \quad \kappa_{\mathrm{S}}=63.4, \quad k_{r o}^{\mathrm{N}}=15(\mathrm{~cm} / \mathrm{mass} \% / \mathrm{sec})
$$

Figure 10 shows the relation between $k_{r}^{\mathrm{N}}$ and $Y$, where,

$$
Y \equiv 1+161 \cdot a_{\mathrm{o}}+63.4 \cdot a_{\mathrm{S}}
$$

The relations between the value of $k_{r}^{\mathrm{N}}$ obtained by three systems and $Y$ can be closely resembles a straight line with a slope of -2.0 . The value of $k_{r o}^{\mathrm{N}}$ is considerably larger than that of previous studies ${ }^{1,4,5)}$ made at $1 \mathrm{~atm}$, and similar to the value reported by Harada and Janke. ${ }^{10}$ )

The values of $k_{r}^{\mathrm{N}}$ in $\mathrm{Fe}-20$ mass $\% \mathrm{Cr}-0.2 \mathrm{mass} \% \mathrm{C}$ system are indicated by solid squares in Fig. 10. These values are plotted just a little above the straight line with an overall slope of -2.0 . Using the value reported by

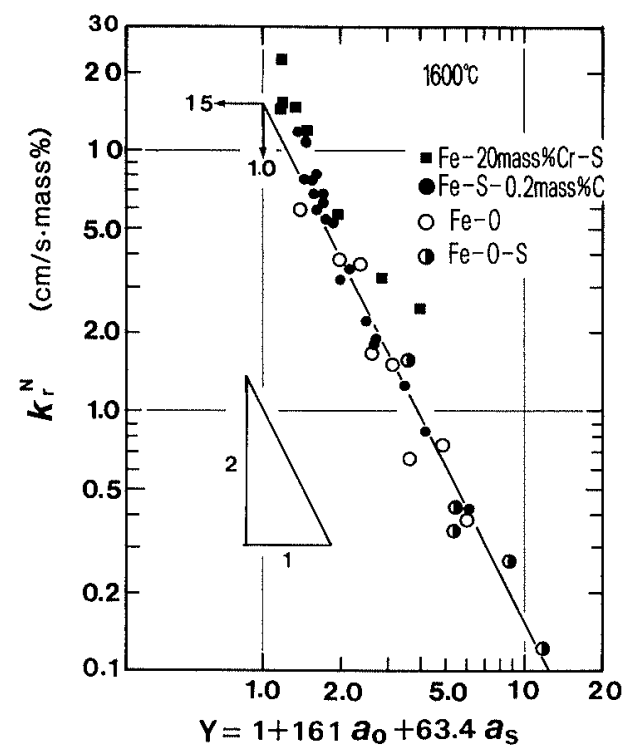

Fig. 10. Relation between chemical reaction rate constant, $k_{r}^{\mathrm{N}}$, of nitrogen removal and $Y$. 
Wada and Pehlke ${ }^{16)}$ for $f_{\mathrm{N}}$ calculation, the relation between $k_{r}^{\mathrm{N}}$ and $Y$ is in good agreement with this straight line. Macroscopically, the nitrogen removal reaction is presumed to proceed by the same mechanism, irrespective of chromium content.

A discussion of the chemical reaction rate constant for carbon removal follows. Blowing the $\mathrm{Ar}-\mathrm{CO}-\mathrm{CO}_{2}$ mixture to the liquid iron surface, resulted in an oxygen content increase in Regions-I and -II. It is therefore not reasonable to conclude that the carbon removal reaction is controlled by the mass transfer of oxygen in the liquid iron, particularly in regions where the carbon content is $100 \mathrm{ppm}$ or lower. It is, rather, assumed that the reaction progresses in the regions through the mixed control of the mass transfer of carbon and $\mathrm{CO}$ and the chemical reaction expressed as Eq. (19).

Substituting the following values into Eqs. (14) and (15), the value of $k_{r}^{\mathrm{C}}$ can be determined from $k_{o v}^{\mathrm{C}}$ in the ultra low-sulfur liquid iron at the pressure of $10 \mathrm{mmHg}$. The unit was unified in the calculation to decide of the value of $k_{r}^{\mathrm{C}}$.

$k_{g}=2 \times 10^{-4}\left(\mathrm{~mol} / \mathrm{cm}^{2} / \mathrm{sec} / \mathrm{atm}\right), \quad k_{\mathrm{C}}=0.048(\mathrm{~cm} / \mathrm{sec})$

The value of $k_{\mathrm{C}}$ was compensated by Eq. $(22)^{15)}$ using the value of $D_{X},{ }^{17)}$ and the value of $k_{g}$ was equal to that of the nitrogen removal because the conditions of gas blowing were the same:

$$
k_{\mathrm{C}}=\left(\frac{D_{\mathrm{C}}}{D_{\mathrm{N}}}\right)^{4 / 3} \cdot k_{\mathrm{N}}
$$

where, $D_{X}$ : diffusivity of $X$ element in liquid iron.

$$
\begin{aligned}
& D_{\mathrm{C}}=8.5 \times 10^{-5}\left(\mathrm{~cm}^{2} / \mathrm{sec}\right)^{17)} \\
& D_{\mathrm{N}}=9.0 \times 10^{-5}\left(\mathrm{~cm}^{2} / \mathrm{sec}\right) .{ }^{17)}
\end{aligned}
$$

Figure 11 shows the relation between $k_{r}^{\mathrm{C}}$ and oxygen content. The value of $k_{r}^{\mathrm{C}}$ decreases with the increase of oxygen content.

The curves in the figure indicate the oxygen content

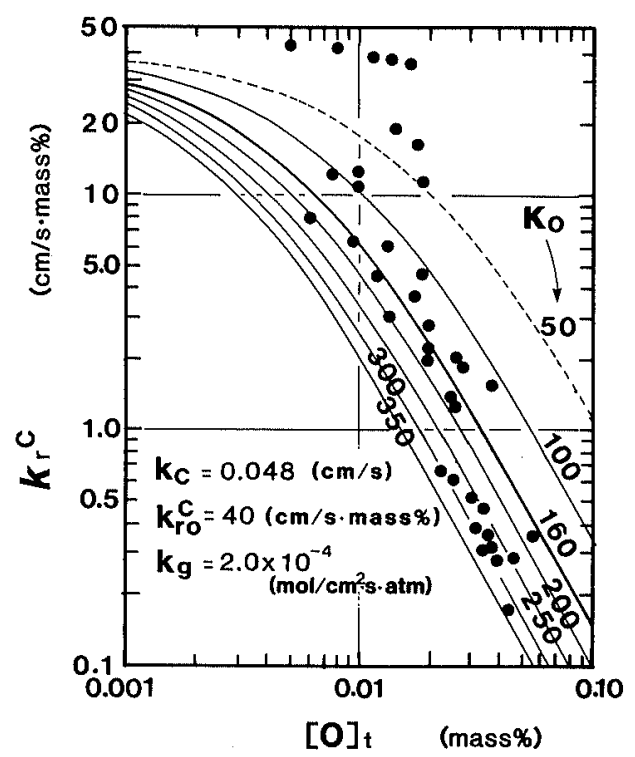

Fig. 11. Relation between chemical reaction rate constant, $k_{r}^{\mathrm{c}}$, of carbon removal and oxygen content at various times. dependence of $k_{r}^{\mathrm{C}}$, the value of which is calculated by Eq. (20) substituting the following values:

$$
\begin{aligned}
& k_{r o}^{\mathrm{C}}=40(\mathrm{~cm} / \mathrm{mass} \% / \mathrm{sec}) \\
& \kappa_{\mathrm{O}}=50-350 .
\end{aligned}
$$

The calculated value of $k_{r}^{\mathrm{C}}$ when $\kappa_{\mathrm{O}}$ is 100 to $300 \mathrm{can}$ roughly explain the oxygen content dependence of the experimental values.

In the case of various sulfur content, the value of $k_{o v}^{\mathrm{C}}$ in Region-I is also calculated for comparison with that of the observed values. The calculated value is shown by the curved line in Fig. 7.

The calculated values used are as following values and the value of $\kappa_{\mathrm{S}}$ is used as a parameter.

$$
\begin{aligned}
& {[\mathrm{O}]_{\text {ave. }}=a_{\mathrm{O}}=0.0075 \text { mass } \%,} \\
& k_{r o}^{\mathrm{C}}=40(\mathrm{~cm} / \mathrm{mass} \% / \mathrm{sec}), \\
& \kappa_{\mathrm{O}}=160 .
\end{aligned}
$$

The observed value of $k_{o v}^{\mathrm{C}}$ thus agree well with the calculated one when the $\kappa_{\mathrm{S}}$ is approximately equal to $40-60$.

Figure 9 shows the oxygen content dependence of $k_{o v}^{\mathrm{C}}$ observed in the experiments conducted under high vacuum pressure at an almost constant oxygen content. In this case, $k_{o v}^{\mathrm{C}}$ is calculated by assuming that $k_{q}$ is much larger than $k_{r o}^{\mathrm{C}}$ and the carbon removal reaction proceeds controlled by the combination of the mass transfer of carbon and the interfacial chemical reaction. In this case, the value of $k_{r o}^{\mathrm{C}}$ used is equal to $40(\mathrm{~cm} / \mathrm{mass} \% / \mathrm{sec})$ and $\kappa_{\mathrm{O}}$ is used as parameter.

The observed value of $k_{o v}^{\mathrm{C}}$ thus agree roughly with the calculated one when the value of $\kappa_{\mathrm{O}}$ is equal to $160-200$. Also, in this case, the value of $k_{o v}^{\mathrm{c}}$ assumes a maximum value relative to oxygen content.

Accordingly, when the chemical reaction for $\mathrm{CO}$ product described by Eq. (19) is the rate controlling step, the value of $k_{o v}^{\mathrm{C}}$ is given by Eq. (23), and if $a_{\mathrm{O}}$ and $a_{\mathrm{S}}$ are approximated by mass $\%[\mathrm{O}]$ and mass $\%[\mathrm{~S}]$, respectively, the oxygen content at which $k_{o v}^{\mathrm{C}}$ assumes a maximum value is given by Eq. (24).

$$
\begin{aligned}
& k_{o v}^{\mathrm{C}}=\frac{k_{r o}^{\mathrm{C}}}{\left(1+\kappa_{\mathrm{S}} \cdot a_{\mathrm{S}}+\kappa_{\mathrm{O}} \cdot a_{\mathrm{O}}\right)^{2}} \\
& \operatorname{mass} \%[\mathrm{O}]^{\text {Max. }}=\frac{1+\kappa_{\mathrm{S}} \cdot \operatorname{mass} \%[\mathrm{~S}]}{\kappa_{\mathrm{O}}}
\end{aligned}
$$

The mechanisms of nitrogen and carbon removal through the surface of liquid iron have been studied on the basis of the influence of oxygen and sulfur content on the overall reaction rate constants in low-nitrogen and low-carbon regions.

Since the overall reaction rates of nitrogen and carbon removal depend on oxygen and sulfur content, both chemical reactions are considered to proceed according to the combination of the adsorbed elements. Then, dependence of both chemical reaction rate constants on $a_{\mathrm{O}}$ and on $a_{\mathrm{S}}$ can be satisfactorily explained by using the respective values of the adsorption coefficients $\kappa_{0}$ and $\kappa_{\mathrm{S}}$. The value of $\kappa_{\mathrm{O}}$ is 100 to 300 and of $\kappa_{\mathrm{S}}$ is 40 to 65 . 


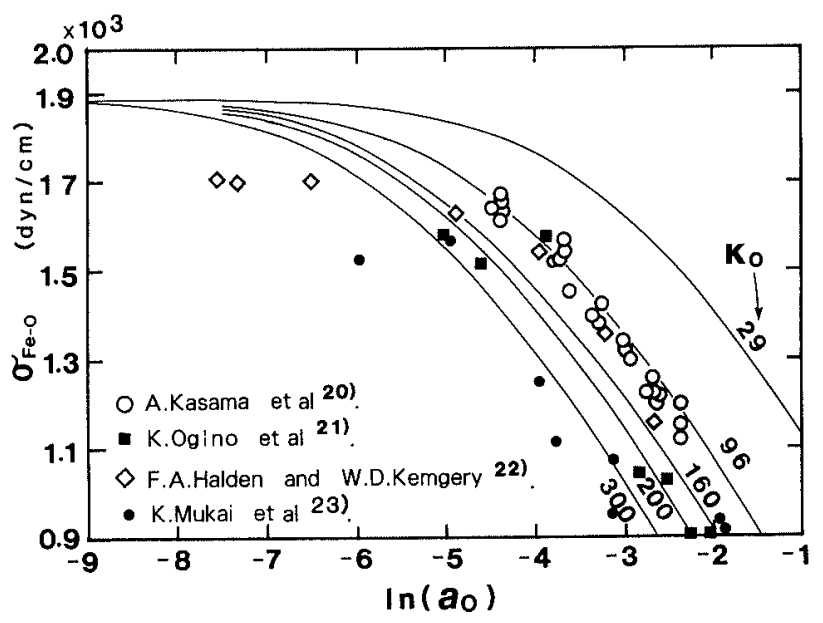

Fig. 12. Relation between $\sigma_{\mathrm{Fe}-\mathrm{O}}$ and $\ln \left(a_{\mathrm{O}}\right)$.

The values of $\kappa_{X}$ were respectively reported by Cramb and Belton ${ }^{18)}$ and Sain and Belton ${ }^{19)}$ as the following equations:

$$
\begin{aligned}
& \log \left(\kappa_{\mathrm{O}}\right)=11370 / T-4.09^{18)} \\
& \log \left(\kappa_{\mathrm{S}}^{\text {[C]sat. }}\right)=3600 / T-0.57^{19)}
\end{aligned}
$$

where, $\kappa_{\mathrm{S}}^{[\text {[C]sat. }}$ t the value of $\kappa_{\mathrm{S}}$ in carbon saturated iron.

According to these equations, the value of $\kappa_{X}$ in $1600^{\circ} \mathrm{C}$ is calculated as follows, but the value of $k_{\mathrm{S}}^{[\mathrm{C}] \mathrm{s} a t}$ is corrected with the activity coefficient of sulfur, $f_{\mathrm{S}}{ }^{13)}$ in comparison with that in low carbon content iron melt.

$$
\begin{aligned}
& \kappa_{\mathrm{O}}=96, \\
& \kappa_{\mathrm{S}}=\kappa_{\mathrm{S}}^{[\mathrm{C}] \text { sat. }} / f_{\mathrm{S}}=56 .
\end{aligned}
$$

The value of $\kappa_{0}$ estimated in the present work was 1.7-2.1 times greater than this value, but the estimated value of $\kappa_{\mathrm{S}}$ in present work was in good agreement with that of the corrected value.

Based on the relation between the surface tension of liquid iron, $\sigma_{\mathrm{Fe}-0}$, and $a_{\mathrm{O}},{ }^{20-23)}$ the value of $\kappa_{\mathrm{O}}$ is now discussed.

The relation between $\sigma_{\mathrm{Fe}-\mathrm{O}}$ and $a_{\mathrm{O}}$ is expressed by Gibbs's adsorption equation as Eq. (27).

$$
\sigma_{\mathrm{Fe}-\mathrm{o}}=\sigma_{\mathrm{Fe}}-\Gamma_{\mathrm{o}} \cdot R \cdot T \cdot \ln \left(1+\kappa_{\mathrm{o}} \cdot a_{\mathrm{O}}\right)
$$

where, $\Gamma_{\mathrm{o}}\left(\mathrm{mol} / \mathrm{cm}^{2}\right)=1.92 \pm 0.24 \times 10^{-920)}$

$$
\left.\sigma_{\mathrm{Fe}}(\mathrm{dyn} / \mathrm{cm})=1890 .^{20}\right)
$$

Figure 12 shows that the relation between the value of $\sigma_{\mathrm{Fe}-\mathrm{O}}$ and $a_{\mathrm{O}}$, and the curved lines show the calculated values according to Eq. (27) when $\kappa_{O}$ is used as a parameter.

The dependence of $\sigma_{\mathrm{Fe}-\mathrm{o}}$ observed values on $a_{\mathrm{O}}$ is in good agreement with that of the calculated lines when $\kappa_{0}$ is about 96 to 200 . Those values are similar to that of estimated in the present work. However, the value of $\kappa_{\mathrm{O}}$ can not be determined as a specific value.

Oxygen is an element that reacts with carbon in the carbon removal reaction. The behavior of oxygen in this carbon removal reaction must be further investigated through more accurate experiments.

\section{Conclusions}

The kinetics of nitrogen and carbon removal through a liquid iron surface by blowing argon gas mixture under reduced pressure have been studied using a vacuum induction furnace at $1600^{\circ} \mathrm{C}$.

The results obtained are as follows:

(1) In the range of nitrogen content less than $50 \mathrm{ppm}$, the nitrogen removal reaction was described as a second-order reaction with respect to nitrogen content in liquid iron. The overall reaction rate constant, $k_{o v}^{\mathrm{N}}$ decreased with the increase of total pressure and oxygen and sulfur content.

(2) Assuming that the nitrogen removal reaction progresses by a mixed control and that the chemical reaction for nitrogen gas formation is caused by adsorbed nitrogen atoms, the chemical reaction rate constant, $k_{r}^{N}$, and the adsorption coefficient of oxygen, $\kappa_{\mathrm{O}}$, and of sulfur, $\kappa_{\mathrm{S}}$, are estimated as follows:

$$
k_{r}^{\mathrm{N}}=15(\mathrm{~cm} / \mathrm{mass} \% / \mathrm{sec}), \quad \kappa_{\mathrm{O}}=161, \quad \kappa_{\mathrm{S}}=63.4 .
$$

In the $\mathrm{Fe}-20$ mass $\% \mathrm{Cr}-0.2$ mass $\%-\mathrm{S}$ system, the value of $k_{r}^{\mathrm{N}}$ is expressed macroscopically by the same equation estimated in the system of $\mathrm{Fe}-\mathrm{O}-\mathrm{S}$. It is concluded that the mechanism of nitrogen removal was the same irrespective of chromium content.

(3) With carbon content of less than $200 \mathrm{ppm}$, the overall reaction rate constant, $k_{o w}^{\mathrm{C}}$, assumes a maximum value relative to oxygen content with or without the gas blowing, and $k_{o v}^{\mathrm{c}}$ decreases with the increase of sulfur content under $\mathrm{Ar}-\mathrm{CO}-\mathrm{CO}_{2}$ blowing.

(4) It is therefore concluded that the chemical reaction for $\mathrm{CO}$ gas formation at the interface is caused by the adsorbed carbon and adsorbed oxygen. Dependences of the chemical reaction rate constant on oxygen and sulfur content could thus be explained by the value of the adsorption constants of $\kappa_{\mathrm{O}}$ and $\kappa_{\mathrm{S}}$, respectively, the value of $\kappa_{\mathrm{O}}$ is about 100 to 300 and of $\kappa_{\mathrm{S}}$ is about 40 to 65 , respectively. Those values are similar to those estimated in the nitrogen desorption.

\section{Nomenclature}

$A:$ area of gas/metal interface

$D_{X}$ : diffusivity of element $X$ or molecule $X$

$K$ : equilibrium constant

$P_{\text {total }}:$ total pressure

$P_{X}^{b}$ : partial pressure of $X$ molecule in gas phase

$P_{X}^{i}:$ partial pressure of $X$ molecule at the interface

$R$ : gas constant

$T:$ temperature

$V:$ volume of liquid iron

$[X]_{b}(=[X]):$ content of element $X$ in liquid iron bulk

$[X]_{e}$ : equilibrium content of element $X$ in liquid iron with gas phase

$[X]_{i}$ : content of element $X$ in liquid iron at the surface

$[X]_{l}$ : equilibrium content of element $X$ in liquid iron at the surface with $P_{X}^{i}$

$[X]_{0}$ : initial content of element $X$ in liquid 
iron

$[X]_{t}$ : content of element $X$ in liquid iron at time $t$

$a_{X}$ : activity of element $X$ in liquid iron

$f_{X}$ : activity coefficient of element $X$ in liquid iron

$k_{g}$ : mass transfer coefficient in gas diffusion boundary layer

$k_{X}$ : mass transfer coefficient of element $X$ in metal diffusion boundary layer

$k_{o v}^{X}$ : overall removal reaction rate constant of element $X$ from liquid iron

$k_{r o}^{X}$ : chemical reaction rate constant at the surface of element $X$ in pure liquid iron

$k_{r}^{X}$ : chemical reaction rate constant at the surface of element $X$ in liquid iron

$k_{\text {[N] }}$ : apparent chemical reaction rate constant for nitrogen removal

$\kappa_{X}$ : adsorption coefficient of element $X$ in liquid iron

$X$ : adsorption atom or adsorption molecule of $X$

$\sigma_{\mathrm{Fe}}$ : surface tension of pure liquid iron

$\Gamma_{\mathrm{o}}$ : surface excess of oxygen

\section{REFERENCES}

1) S. Ban-ya, T. Shinohara, H. Tozaki and T. Fuwa: Tetsu-toHagané, 60 (1974), 1443.

2) K. Suzuki, K. Mori and Y. Itoho: Tetsu-to-Hagané, 55 (1969), 877.

3) K. Narita, S. Koyama and M. Matsushima: Tetsu-to-Hagané, 57 (1971), 2207
4) R. J. Fruehan and L. J. Martonik: Metall. Trans. B, 11 (1980), 615.

5) M. Bryne and G. R. Belton: Metall. Trans. B, 14 (1983), 441.

6) M. Takahashi, H. Matsuda, H. Ohokuma, M. Sano and K. Mori: Tetsu-to-Hagané, 72 (1986), 419.

7) H. Nomura and K. Mori: Tetsu-to-Hagané, 58 (1972), 29.

8) K. Suzuki, K. Mori, T. Kitagawa and T. Shibayama: Tetsuto-Hagané, 62 (1976), 354.

9) T. Choh, T. Moritani and M. Inoue: Tetsu-to-Hagané, 64 (1978), 701.

10) T. Harada and D. Janke: Steel Res., 60 (1989), 337.

11) Y. Kishimoto, K. Yamaguchi, Y. Kato, T. Sakuraya and T. Fujii: CAMP-ISIJ, 2 (1989), 1129.

12) K. Harashima, S. Mizoguchi, H. Kajioka and K. Sakakura: Tetsu-to-Hagané, 73 (1987), 1559.

13) Selected Equilibrium Values for Steelmaking Reactions, The 19th Committee (Steelmaking), The Japan Society for the Promotion of Science (JSPS), Tokyo, (1984).

14) K. Harashima, T. Mizoguchi and H. Kajioka: Tetsu-to-Hagané, 74 (1988), 449.

15) G. H. Geiger and D. R. Poirier: Transport Phenomena in Metallurgy, Addison-Wesley, Mass., (1980).

16) H. Wada and R. D. Pehlke: Metall. Trans. B, 8 (1977), 443.

17) Y. Kawai and Y. Shiraishi: Handbook of Physico-chemical Properties at High Temperatures, ISIJ, Tokyo. (1988).

18) A. W. Cramb and G. R. Belton: Metall. Trans. B, 12 (1981), 699.

19) R. D. Sain and G. R. Belton: Metall. Trans. B, 9 (1978), 403.

20) A. Kasama, A. Mclean, W. A. Miller, Z. Morita and M. J. Ward: Can. Metall. Q., 22 (1983), 9.

21) K. Ogino, S. Hara, T. Miwa and S. Kimoto: Tetsu-to-Hagané, 65 (1979), 2012.

22) F. A. Halden and W. D. Kingery: J. Phys. Chem., 59 (1955), 557.

23) K. Mukai, T. Kato and H. Sakao: Tetsu-to-Hagané, 59 (1973), 55. 